Check for updates

Cite this: RSC Adv., 2019, 9, 7635

\title{
Mechanism and stereoselectivity in NHC-catalyzed $\beta$-functionalization of saturated carboxylic ester $\dagger$
}

\begin{abstract}
Yan Li (iD* and Zhiqiang Zhang (D)
To understand the mechanism and origin of the stereoselectivity of the $[3+2]$ annulation reaction between a carboxylic ester and an isatin generating spirooxindole lactone catalyzed by $\mathrm{N}$ heterocyclic carbene (NHC), density functional theory (DFT) calculations have been carried out. DFT results indicate that the catalytic cycle begins with the coupling of the catalyst with benzotriazole ester, followed by $\alpha$-deprotonation to produce the enolate intermediate. The subsequent 1,4-proton transfer affords the homoenolate intermediate. The next crucial step is the stereoselective $\mathrm{C}-\mathrm{C}$ bond formation. Then proton transfer takes place leading to the formation of the lactone intermediate. Finally, the elimination of the catalyst furnishes the final product. The presence of 1-hydroxybenzotriazole (HOBt) dramatically accelerates the proton transfer step. More importantly, $\mathrm{HOBt}$ has a non-negligible impact on stereoselective $\mathrm{C}-\mathrm{C}$ bond formation, and the $S R$-configured product is the major stereoisomer of the annulation product, which is in good agreement with the experimental observations. The differential $\pi \cdots \pi$ stacking, $\mathrm{C}-\mathrm{H} \cdots \pi$, lone pair (LP) $\cdots \pi$ and repulsion interactions are found to be responsible for the stereoselectivity. The obtained mechanistic insights should provide valuable information for understanding the important roles of the NHC catalyst and HOBt additive and be helpful for designing better NHC catalysts for this kind of reaction.
\end{abstract}

Received 14th December 2018 Accepted 28th February 2019

DOI: $10.1039 / \mathrm{c} 8 \mathrm{ra} 10262 \mathrm{~g}$

rsc.li/rsc-advances reactions. ${ }^{6}$ Indeed, many cycloaddition reactions using NHC catalysts affording various heterocycles have been reported, including the $[2+2], 7[2+4],{ }^{8}[3+n](n=2,3,4),{ }^{9}$ and $[4+n](n=$ $2,3)^{10}$ cycloadditions.

Recently, Xu et al. developed a catalytic protocol for the synthesis of spirooxindole lactones via $\beta$-functionalization of saturated carboxylic esters in tetrahydrofuran (THF) solvent at room temperature. ${ }^{11}$ It was found that the reaction of carboxylic esters with isatins could be effectively catalyzed by using NHC as catalyst and 1-hydroxybenzotriazole (HOBt) as additive. Additional experiments showed that HOBt is important in the current reaction because the yields and enantio- and diastereo-selectivities were higher in the presence of HOBt as compared with that in the absence of HOBt.

However, the mechanism of the NHC-catalyzed $[3+2]$ annulation reaction between carboxylic esters and isatins (Scheme 1) has not been studied theoretically until now. How does the catalytic reaction proceed? Which step is the stereocontrolling step? What role does the additive HOBt play? In this work, we will examine the NHC-catalyzed $[3+2]$ annulation reaction between a carboxylic ester and an isatin using density functional theory calculations. We concentrate on the reaction mechanism as well as the origin of stereoselectivity. The objective of this work is to provide mechanistic insights for the catalyzed reaction shown in Scheme 1 and explain the enhanced
School of Chemical Engineering, University of Science and Technology Liaoning, Anshan 114051, P. R. China. E-mail: snow2007liyan@163.com; Fax: +86-4125929627; Tel: +86-18741219506

$\dagger$ Electronic supplementary information (ESI) available. See DOI: $10.1039 / \mathrm{c} 8 \mathrm{ra10262g}$ 

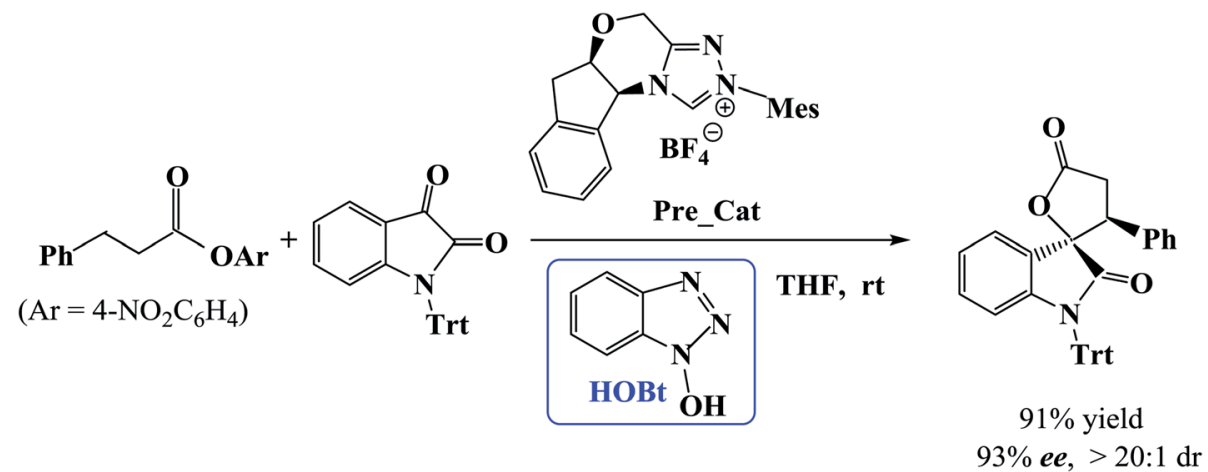

Scheme $1 \mathrm{NHC}$-catalyzed [3+2] annulation reaction

stereoselectivity in the presence of HOBt in comparison to that in its absence.

\section{Computational methods}

Geometries of all the structures involved in the reaction were optimized using the M06-2X functional ${ }^{12}$ with the $6-31 \mathrm{G}(\mathrm{d})$ basis set. Previous studies have confirmed the reliability of the chosen M06-2X functional. ${ }^{13}$ Frequency calculations were performed in order to check the minimum has all real frequencies while the transition state has one and only one imaginary frequency and to obtain thermodynamic corrections at $298.15 \mathrm{~K}$ and $1 \mathrm{~atm}$ pressure. In order to confirm the connection of the transition states and the desired minima, intrinsic reaction coordinate (IRC) calculations were also performed. ${ }^{14}$ To account for solvent effect, single-point energy calculations were carried out at the M06-2X/6-311++G(d,p) level in the solvent phase modeled by the Cramer-Truhlar continuum solvation model $\mathrm{SMD}^{15}$ in tetrahydrofuran (THF, $\varepsilon=7.43$ ). To assign the atomic charges, natural bond orbital (NBO) analyses were also carried out. ${ }^{16}$ All calculations were carried out with the Gaussian 09 software package. ${ }^{17}$

\section{Results and discussion}

\subsection{Reaction mechanism}

In this section, we present and discuss the detailed results for the $[3+2]$ cycloaddition reaction between 4-nitrophenyl 3phenylpropanoate and isatin depicted in Scheme 1. On the basis of our calculation results, the detailed mechanism for the whole catalytic cycle is presented in Scheme 2. Before considering the possible reaction pathways of the current reaction, we explore first the actual catalyst in the current reaction. As shown in Scheme 2, in the presence of cesium carbonate $\mathrm{Cs}_{2} \mathrm{CO}_{3}$, the catalyst precursor Pre_Cat will undergo deprotonation to form the active $\mathbf{N H C}$ catalyst and release bicarbonate anion $\mathrm{HCO}_{3}{ }^{-} .^{18}$ Experimentally, 4-nitrophenyl 3-phenylpropanoate was used as one substrate (isatin as the other substrate) and 1-hydroxybenzotriazole (HOBt) as an additive. Computationally, we use the benzotriazole ester, depicted in Scheme 2 as one starting reactant because benzotriazole ester can be generated through the reaction of 4-nitrophenyl 3-phenylpropanoate with HOBt.
As presented in Scheme 2, the catalytic reaction proceeds via six steps: (1) the additon of the active catalyst NHC to benzotriazole ester $\mathbf{R} \mathbf{1}$ to form the acyl azolium intermediate IM1 and release $\mathrm{OBt}^{-}$; (2) the deprotonation of the $\alpha-\mathrm{C}-\mathrm{H}$ in IM1 to generate the enolate intermediate IM2; (3) the proton transfer of IM2 leads to the homoenolate intermediate IM3; (4) the stereoselective carbon-carbon bond formation process which can be achieved from the addition of isatin R2 to IM3 leading to intermediate IM4; (5) the proton transfer followed by the intramolecular lactonization will eventually provide access to the five membered ring intermediate IM6, and (6) the elimination of the NHC catalyst yields the spirooxindole lactone product $\mathbf{P}$ with two chiral carbon atoms. The corresponding free energy profiles and optimized structures are shown in Fig. 1 (steps I-III) and 2 (steps IV-VI). In the following part, the reaction mechanism will be examined in greater detail.

Step I: addition of catalyst NHC to benzotriazole ester R1. As shown in Fig. 1, the reaction is initiated by the coupling of the NHC catalyst with benzotriazole ester R1 leading to the formation of intermediates IM01 and IM01-1 via the respective transition states TS1 and TS1-1. The calculated free energy barriers of TS1 and TS1-1 are $15.6 \mathrm{kcal} \mathrm{mol}^{-1}$ and $18.3 \mathrm{kcal} \mathrm{mol}^{-1}$, respectively. The relative free energy of IM01 and IM01-1 are 6.3 and $9.7 \mathrm{kcal} \mathrm{mol}^{-1}$, respectively. Clearly, formation of intermediate IM01 is both kinetically and thermodynamically much more favorable than IM01-1. Therefore, the description herein focuses on the reaction pathways associated with intermediate IM01. As shown in Fig. 1, for the transformation of TS1 $\rightarrow$ IM01, the distance of $\mathrm{C} 1-\mathrm{C} 2$ bond shortens from $2.239 \AA$ to $1.560 \AA$, while that of $\mathrm{C} 2-\mathrm{O}$ bond increases from $1.447 \AA$ to $1.658 \AA$. These results demonstrate that the formation of C1-C2 bond is occurred together with the cleavage of $\mathrm{C} 2-\mathrm{O}$ bond. Subsequent dissociation of $\mathrm{OBt}^{-}$from IM01 leads to the acyl azolium intermediate IM1.

Scheme 3 shows the NBO charge analysis results. As can be seen from Scheme 3, for Cat $+\mathbf{R 1} \rightarrow$ IM01 process, the positive charge value on the $\mathrm{C} 1$ atom increases from $0.148 e$ to $0.414 e$, while that on the $\mathrm{C} 2$ atom decreases from $0.840 e$ to $-0.041 e$. Furthermore, the negative charge value on the $\mathrm{N}$ atom decreases from $-0.489 e$ to $-0.415 e$, while that of the carbonyl oxygen $\mathrm{O} 3$ atom increases from $-0.543 e$ to $-0.909 e$. These results indicate 


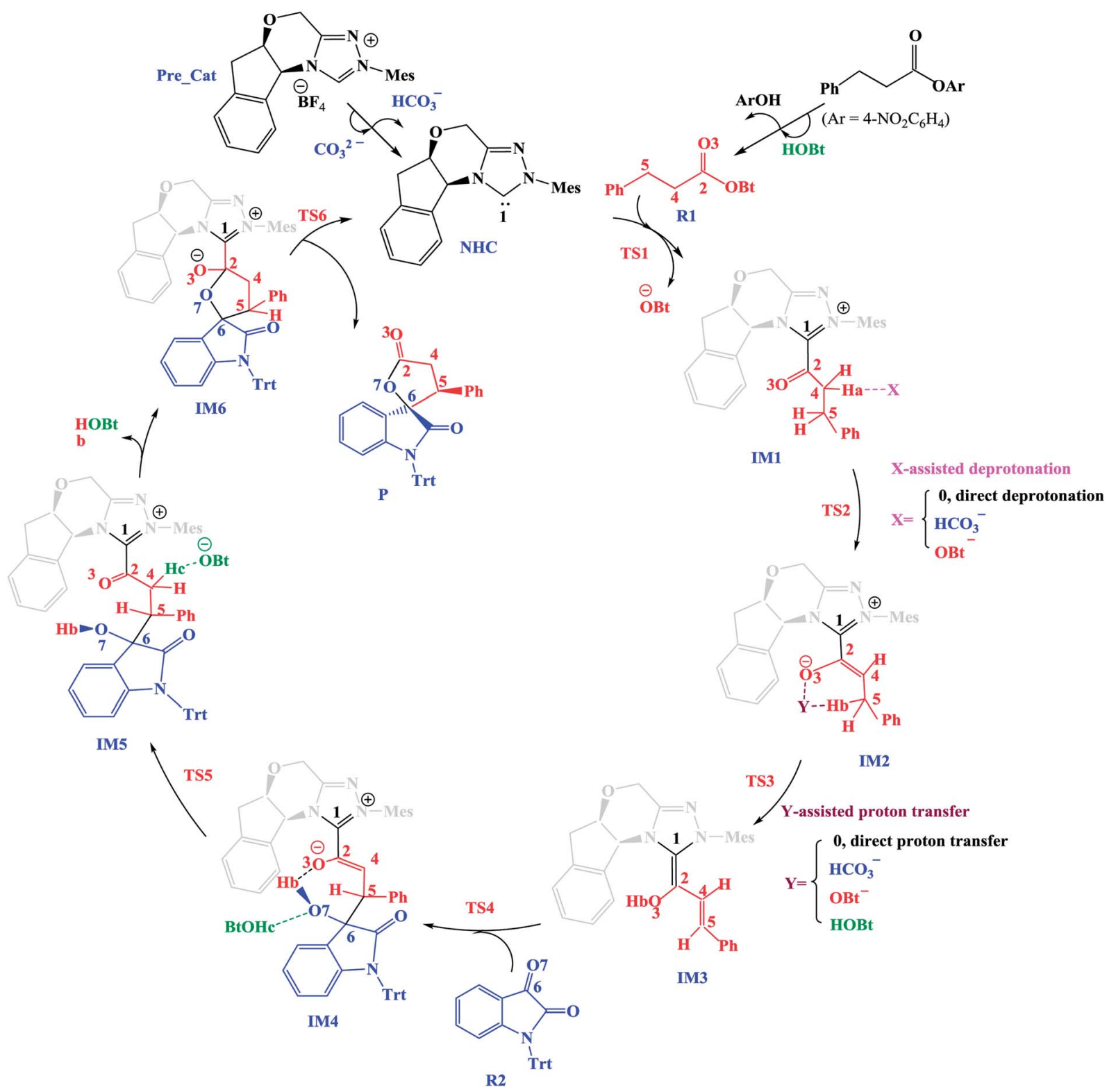

Scheme 2 The key steps involved in the NHC-catalyzed [3+2] annulation reaction.

that the electron density is transferred from Cat to $\mathbf{R} \mathbf{1}$ during the process of Cat $+\mathbf{R 1} \rightarrow$ IM01.

Step II: $\alpha$-C-H deprotonation. From intermediate IM1, $\alpha-\mathrm{C}-$ $\mathrm{H}$ deprotonation occurs to generate the enolate intermediate IM2. Many computational studies have shown that the mediators assisted deprotonation favors the direct deprotonation. ${ }^{19}$ In this work, three possibilities including direct, $\mathrm{OBt}^{-}$and $\mathrm{HCO}_{3}{ }^{-}$ assisted deprotonation have been investigated.

(1) Direct deprotonation. For direct deprotonation, we can not locate the corresponding transition state despite lots of attempts. We performed relax potential energy scan for the C4Ha bond. The corresponding pointwise potential curve was provided in Fig. S1 in the ESI. $\uparrow$ Fig. S1† clearly shows that the energy keeps increasing when the Ha atom getting farther from the C4 atom of IM1. The high energy barrier estimated for direct deprotonation process $\left(\sim 70 \mathrm{kcal} \mathrm{mol}{ }^{-1}\right)$, indicates that the direct deprotonation pathway is kinetically unfeasible. In view of this, a mediator assisted deprotonation, facilitated by the previously formed $\mathrm{OBt}^{-}$(or $\mathrm{HCO}_{3}{ }^{-}$) has been examined.

(2) $\mathrm{OBt}^{-}$assisted deprotonation. The anion $\mathrm{OBt}^{-}$generated in the first step can remove the hydrogen atom (Ha) in IM1 via the transition state TS2 to generate intermediate IM2. The calculated free energy barrier is $2.4 \mathrm{kcal} \mathrm{mol}^{-1}$ for TS2 with respect to IM1, demonstrating that the $\mathrm{OBt}^{-}$mediated deprotonation of $\alpha$ $\mathrm{C}-\mathrm{H}$ is a fast process under the experimental conditions. During this process (IM1 $\rightarrow$ TS2 $\rightarrow$ IM2), the distance of C4-Ha bond is elongated from $1.099 \AA$ to $1.372 \AA$ (IM1 $\rightarrow$ TS2), whereas the distance of Ha-O bond is shortened from $1.245 \AA$, to $0.973 \AA$ $($ TS2 $\rightarrow$ IM2 + OBt). These results indicate that the deprotonation process is completed. The transformation from IM1 to IM2 


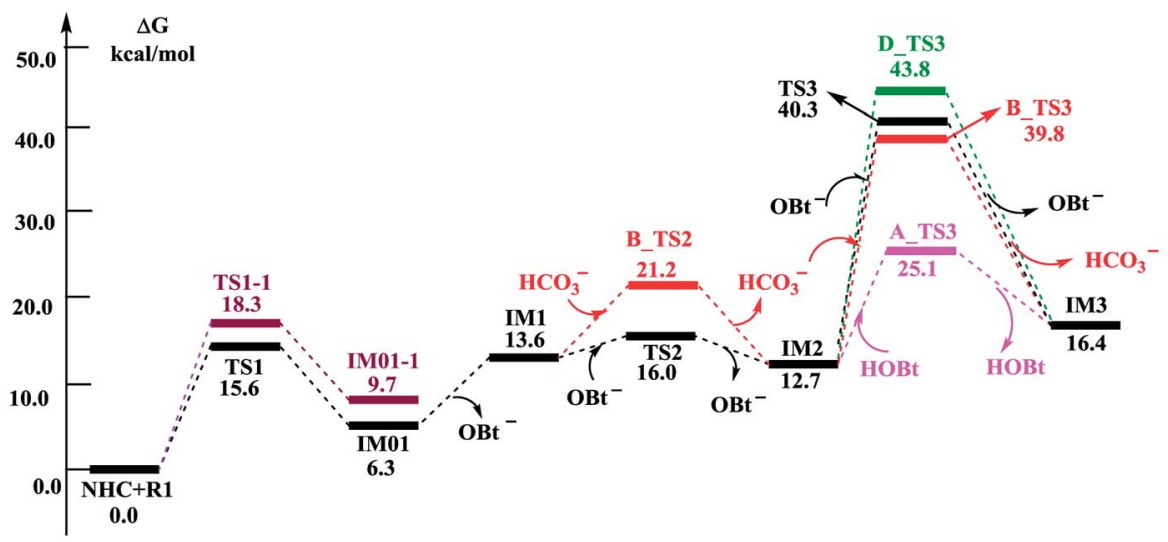

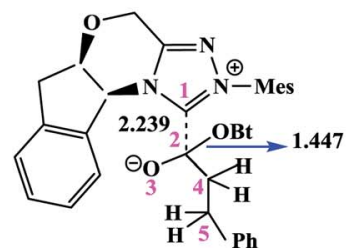

TS1

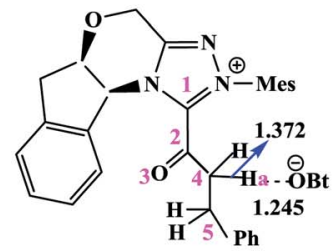

TS2

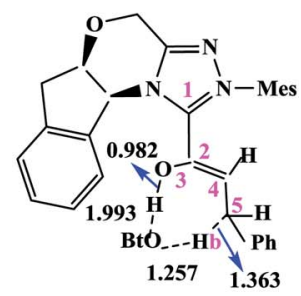

A_TS3

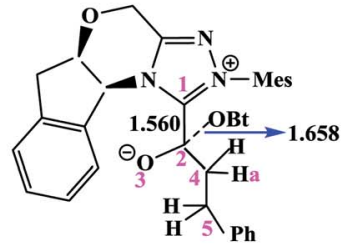

IM01

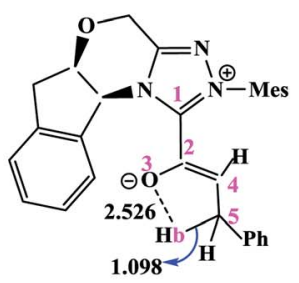

IM2

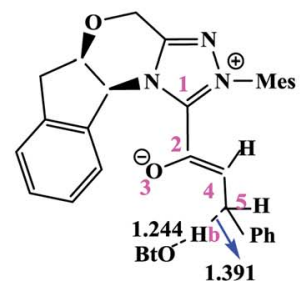

TS3

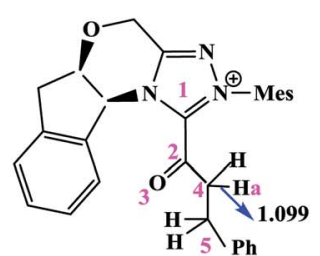

IM1

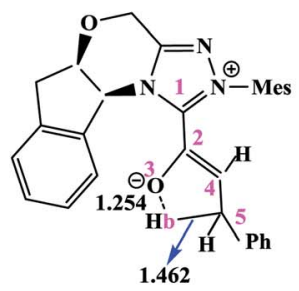

D_TS3

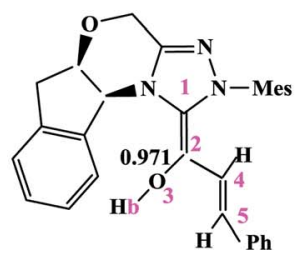

IM3

Fig. 1 Free energy profile obtained at SMD(THF)/M06-2X/6-311++G(d,p) level $\left(\mathrm{kcal} \mathrm{mol}^{-1}\right)$ and optimized structures for steps I-III. Bond lengths are given in $\AA$.

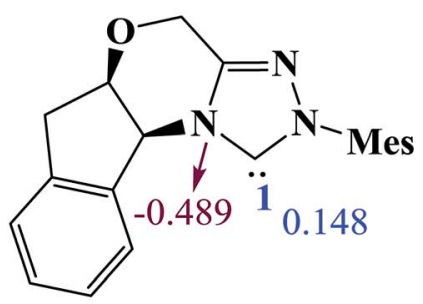

NHC<smiles>CS(=O)(=O)OC(=O)CCc1ccccc1</smiles>

0.840

R1

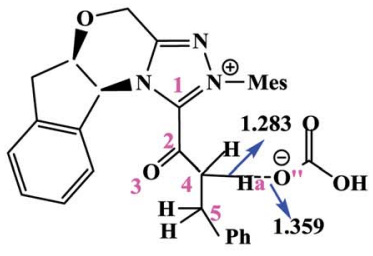

B_TS2

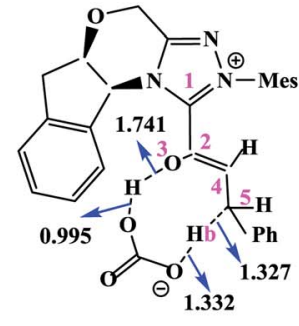

B_TS3

$-0.415$

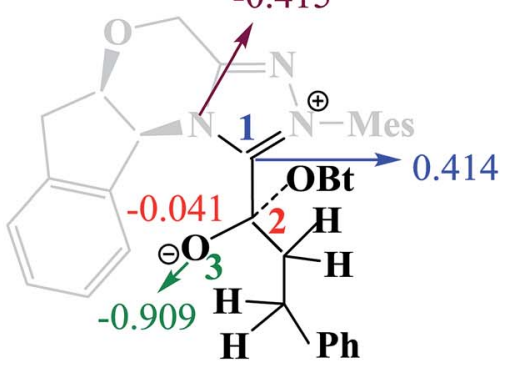

IM01

Scheme 3 The NBO charges of selected atoms in NHC, R1 and IM01 (units of e). 
is found to be slightly exergonic with a reaction energy of $-0.9 \mathrm{kcal} \mathrm{mol}^{-1}$.

(3) $\mathrm{HCO}_{3}{ }^{-}$assisted deprotonation. In another possibility, the previously formed $\mathrm{HCO}_{3}{ }^{-}$was used as promoter. The energy barrier calculated for the $\mathrm{HCO}_{3}{ }^{-}$assisted deprotonation is $7.6 \mathrm{kcal} \mathrm{mol}^{-1}$ via B_TS2. As shown in Fig. 1, the distance of C4Ha bond increases from $1.099 \AA$ in IM1 to $1.283 \AA$ in B_TS2, while that of $\mathrm{Ha}-\mathrm{O}^{\prime \prime}$ bond decreases from $1.359 \AA$ in IM1 to $0.968 \AA$ in $\mathrm{H}_{2} \mathrm{CO}_{3}$.

Taken together, the mediators $\left(\mathrm{BtO}^{-}\right.$and $\mathrm{HCO}_{3}{ }^{-}$) promote the deprotonation process. The most favored proton transfer pathway is found to be that from IM1 to IM2 via TS2 with the assistance of $\mathrm{OBt}^{-}$.

Step III: 1,4-proton transfer. The 1,4-proton transfer of IM2 forms intermediate IM3. Similar to the discussion of step II, both direct and mediator $\left(\mathrm{HCO}_{3}{ }^{-}\right.$, $\mathrm{BtO}^{-}$and $\left.\mathrm{HOBt}\right)$ promoted proton transfer processes have been investigated.

For direct 1,4-proton transfer, migration of the $\mathrm{Hb}$ atom connected to $\mathrm{C} 5$ atom to $\mathrm{O} 3$ atom via the corresponding fivemembered ring transition state D_TS3 with a free energy barrier of $31.1 \mathrm{kcal} \mathrm{mol}^{-1}$ (43.8 kcal mol${ }^{-1}$ with respect to reactants) (Fig. 1). Therefore, direct 1,4-proton transfer in intermediate IM2 is a kinetically inaccessible process under the experimental conditions.

We also calculated the $\mathrm{HCO}_{3}{ }^{-}$and $\mathrm{OBt}^{-}$assisted proton transfer. The corresponding energy profiles are also presented in Fig. 1. However, the high activation energies of B_TS3 $\left(39.8 \mathrm{kcal} \mathrm{mol}^{-1}\right.$ relative to reactants, associated with the $\mathrm{HCO}_{3}{ }^{-}$mediated proton transfer) and TS3 (40.3 kcal mol${ }^{-1}$ relative to reactants, associated with the $\mathrm{OBt}^{-}$mediated proton transfer) indicate that the mediator $\left(\mathrm{HCO}_{3}{ }^{-}\right.$and $\left.\mathrm{BtO}^{-}\right)$has minimal effects on the proton transfer event. Thus these pathways are also kinetically unfavorable, and can be ruled out.

Experimentally, HOBt was used as an additive, promoting us to investigate the HOBt assisted proton transfer process. According to our calculation results, the 1,4-proton transfer proceeds via the seven-membered ring transition state A_TS3 leading to the formation of the homoenolate intermediate IM3 in the presence of HOBt (Fig. 1). Computational results show that the transition state for this process (A_TS3 $\left(25.1 \mathrm{kcal} \mathrm{mol}^{-1}\right)$ ) is much lower in energy than those of the unassisted and the $\mathrm{BtO}^{-}$and $\mathrm{HCO}_{3}{ }^{-}$assisted proton transfer processes (i.e., D_TS3 $\left(43.8 \mathrm{kcal} \mathrm{mol}^{-1}\right)$, B_TS3 $\left(39.8 \mathrm{kcal} \mathrm{mol}^{-1}\right)$ and TS3 $\left.\left(40.3 \mathrm{kcal} \mathrm{mol}^{-1}\right)\right)$. As can be seen from Fig. 1, the $\mathrm{Hb}$ atom migrates from $\mathrm{C} 5$ to $\mathrm{O}$, at the same time, the $\mathrm{H}$ atom transfers from $\mathrm{O}$ to $\mathrm{O} 3$ via the seven-membered ring transition state A_TS3. The bond distances of $\mathrm{C} 5-\mathrm{Hb}, \mathrm{Hb}-\mathrm{O}, \mathrm{O}-\mathrm{H}$ and O3H in A_TS3 are 1.363, 1.257, 1.993 and $0.982 \AA$, respectively, indicating the HOBt mediated 1,4-proton transfer occurs in a concerted manner but not synchronous.

Step IV: the stereoselective $\mathbf{C}-\mathbf{C}$ bond formation. The fourth step is the stereoselective determining step, which involves the addition of the $\mathbf{C} 5$ atom of IM3 to the $\mathbf{C} 6$ atom of $\mathbf{R} 2$ leading to the formation of $\mathrm{C}-\mathrm{C}$ bond. As depicted in Scheme 4, four stereochemically distinct attack modes i.e. (Re, Re), (Re, Si), $(S i$, $\mathrm{Re}$ ) and $(\mathrm{Si}, \mathrm{Si})$ were located resulting into the formation of intermediates IM4(RR\&RS\&SR\&SS), which have two chiral carbon atoms (i.e., C5 and C6). It should be noted that the formation of the $\mathrm{C} 5-\mathrm{C} 6$ bond is concerted with a proton transfer of the enolate proton to the isatin moiety leading to the formation of intermediate IM4. According to experiments, improved enantioselectivity could be achieved when HOBt was used as an additive, ${ }^{11}$ both the non- and HOBt-assisted C-C bond formation pathways have thus been explored.

In the absence of HOBt, the activation energy barriers of this step via transition states D_TS4(RR\&RS\&SR\&SS) are 13.2/20.2/ 14.0/17.9 $\mathrm{kcal} \mathrm{mol}^{-1}\left(29.6 / 36.6 / 30.4 / 34.3 \mathrm{kcal} \mathrm{mol}^{-1}\right.$ with respect to reactants), as shown in Fig. S2. $\dagger$ Considering that the activation energy barrier of D_TS4(RR) is lower than those of D_TS4(RS\&SR\&SS), the reaction pathway associated with D_TS4(RR) should be more favorable than the other pathways. Therefore, the dominant product in the absence of HOBt should be the $R R$ configuration product. This is inconsistent with the experimental results. The experimentally observed major product without the use of HOBt was the SR-stereoisomer of the cycloaddition product. ${ }^{11}$ Considering this inconsistency, more experimental studies are expected to be necessary to better understand the stereoselectivity associated with the reaction, depicted in Scheme 1 in the absence of HOBt.

Since HOBt was used as an additive in experiment, ${ }^{11}$ it might assist in this $\mathrm{C}-\mathrm{C}$ bond formation. We thus have included an explicit molecule of HOBt in this step to form intermediate IM4. Fig. 2 shows that the free energy barriers of this step in the presence of HOBt via transition states TS4(RR\&RS\&SR\&SS) are 9.8/10.2/7.9/12.1 kcal mol ${ }^{-1}\left(26.2 / 26.6 / 24.3 / 28.5 \mathrm{kcal} \mathrm{mol}^{-1}\right.$ relative to reactants), which is found to be lower than the transition states in the absence of HOBt (for details see the ESI, Fig. S2 $\uparrow$ ). To understand this result, we examined the non and HOBt assisted transition state (D_TS4 and TS4) structures (shown in Fig. S3†). As depicted in Fig. S3, † additional interactions such as $\mathrm{O}-\mathrm{H} \cdots \mathrm{O}$ and $\mathrm{O}-\mathrm{H} \cdots \mathrm{N}$ are present in the HOBtassisted transition state compared to the unassisted transition state. These interactions are depicted as follows: $\mathrm{O}-\mathrm{H} \cdots \mathrm{O}(\mathrm{a}, \mathrm{b}, \mathrm{c}$ and d) and $\mathrm{O}-\mathrm{H} \cdots \mathrm{N}(\mathrm{e})$. Moreover, Fig. 2 clearly shows that the energy barrier of TS4(SR) is remarkably lower than those of other configuration transition states (i.e., TS4(RR), TS4(RS) and TS4(SS)), for simplicity of presentation, we discuss the reaction pathways starting from IM4(SR) here (as shown in Fig. 2). Results for the less favorable pathways which feature $R R / R S / S S$ configuration are provided in the ESI (Fig. S4 $\dagger$ ). Intrinsic reaction coordinate (IRC) results for transition state TS4(SR) reveal that the $\mathrm{C} 5-\mathrm{C} 6$ bond formation occurs along with the $\mathrm{Hb}$ atom migration from $\mathrm{O} 3$ to $\mathrm{O} 7$, leading to intermediate IM4(SR). From TS4(SR) to IM4(SR), the distance of C5-C6 bond changes from $2.502 \AA$ to $1.570 \AA$, at the same time, the distance of $\mathrm{O} 3-\mathrm{Hb}$ bond increases from $0.975 \AA$ to $1.426 \AA$, while the $\mathrm{Hb}-\mathrm{O} 7$ bond shortens from $2.136 \AA$ to $1.051 \AA$. The above structural analysis indicates that the C5-C6 bond formation is accompanied by the transformation of the $\mathrm{Hb}$ atom (from $\mathrm{O} 3$ to $\mathrm{O} 7$ ).

Step V: the proton transfer and intramolecular lactamization. As shown in Fig. 2, intermediate IM4(SR) undergoes consecutive proton transfer and intramolecular lactonization to reach intermediate IM6(SR). First, the proton Hc transfers to the $\mathrm{C} 4$ atom generates intermediate IM5(SR). This proton 


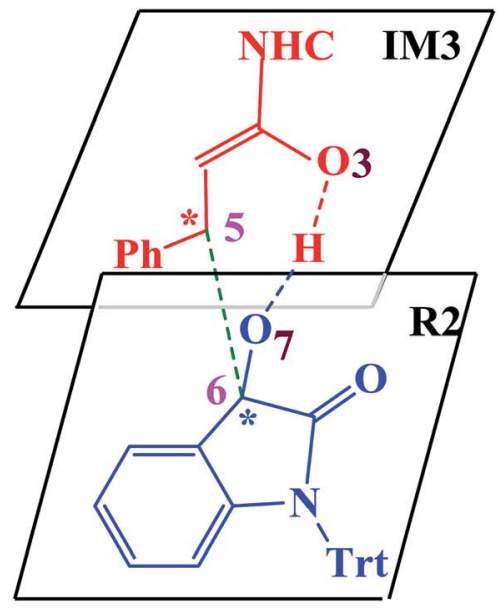

TS4(RR)

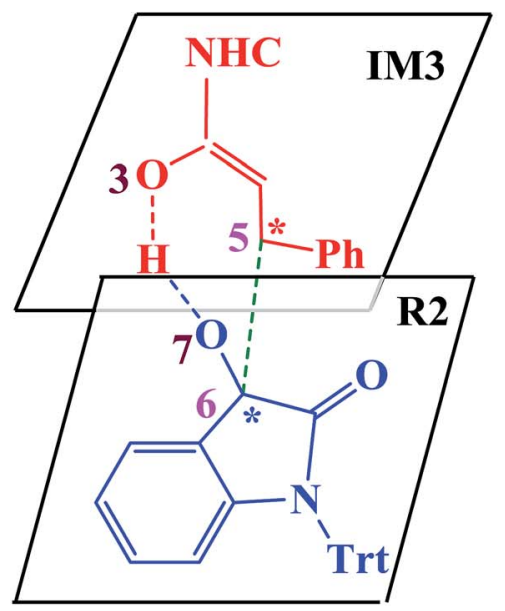

TS4(SR)

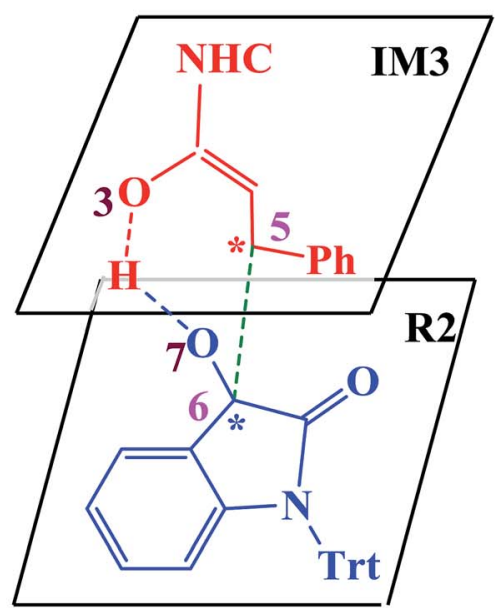

TS4(RS)

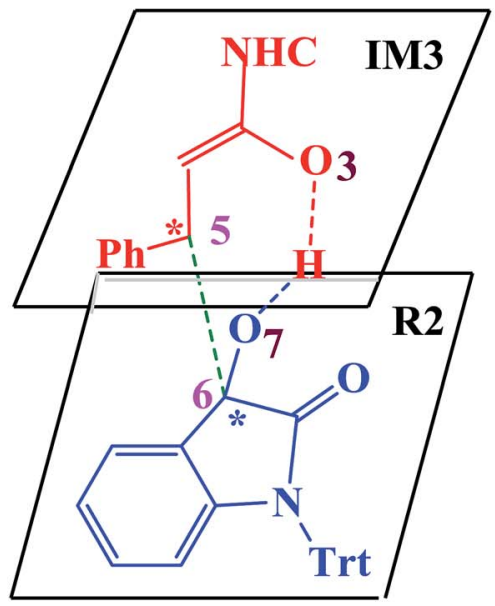

TS4(SS)

Scheme 4 Four attack modes involved in the stereoselectivity determining step (the hydrogen atoms are omitted).

transfer step via transition state TS5(SR) has an activation energy of $10.2 \mathrm{kcal} \mathrm{mol}^{-1}$. For IM4(SR) $\rightarrow$ TS5(SR) $\rightarrow$ IM5(SR) reaction course, the bond distance of $\mathrm{O}^{\prime}-\mathrm{Hc}$ is elongated from $1.300 \AA$ in TS5(SR) to $2.058 \AA$ in IM5(SR), while that of Hc-C4 is shortened from $1.330 \AA$ in TS5(SR) to $1.111 \AA$ in IM5(SR). Subsequently, lactonization of IM5(SR) generates the slightly more stable intermediate IM6(SR). Note that we can not locate the corresponding transition state despite lots of attempts. From IM5(SR) to IM6(SR), the distance of C2-O7 bond shortens from $2.804 \AA$ to $1.523 \AA$.

Step VI: formation of the cycloaddition product. In the final step, NHC catalyst releases from intermediate IM6(SR) affording the final cycloaddition product $\mathbf{P}(\mathbf{S R})$ through the transition state TS6(SR) with an activation energy of $6.0 \mathrm{kcal} \mathrm{mol}^{-1}$. As shown in Fig. 2, the distance of $\mathrm{C} 1-\mathrm{C} 2$ bond is elongated from $1.546 \AA$ in IM6(SR), to $2.031 \AA$ in TS6(SR).

\subsection{Origin of selectivity}

As shown in Fig. 2 and discussed above in step IV, the addition of the homoenolate intermediate IM3 to isatin R2 leading to the formation of $\mathrm{C}-\mathrm{C}$ bond is the stereoselectivity-determining step. Consequently, transition states TS4(RR), TS4(RS), TS4(SR) and TS4(SS) are found to be responsible for determining the stereoselectivity of the entire reaction. The activation energy barriers for generating the $\mathrm{RR} / \mathrm{RS} / \mathrm{SR} / \mathrm{SS}$ configuration products via $\mathbf{T S 4} \mathbf{4 R} / \mathbf{R S} / \mathbf{S R} / \mathbf{S S})$ are calculated to be 26.2/26.6/24.3/28.5 kcal mol${ }^{-1}$ (the energy difference between TS4(RR/RS/SR/SS) and reactants). Obviously, the $S R$ configurational product $\mathbf{P ( S R})$ is the major product, agrees well with the experimental observations. Based on the CurtinHammett Principle,$^{20}$ the product distribution is determined by the standard free energy difference of the stereoselectivitydetermining transition states. The energy difference between 


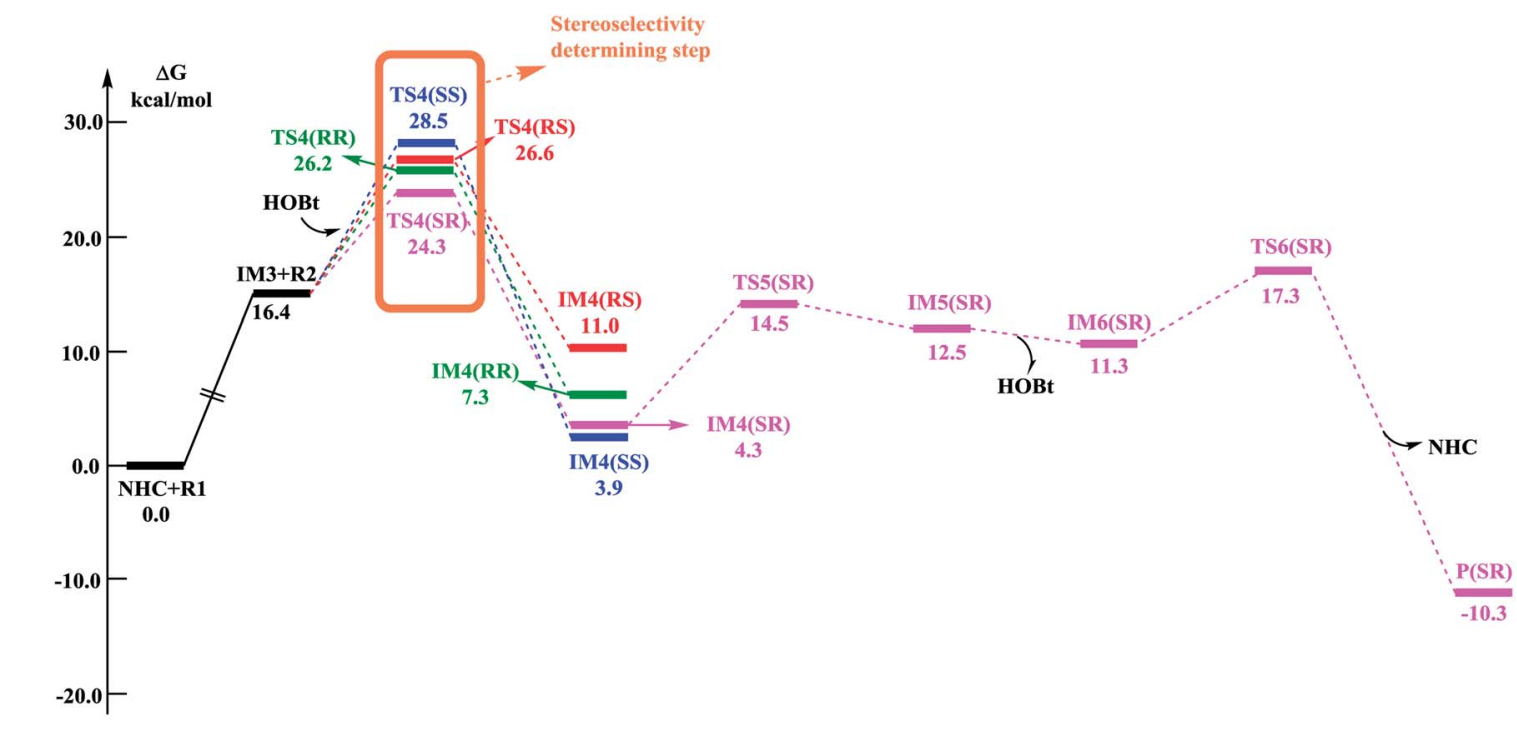

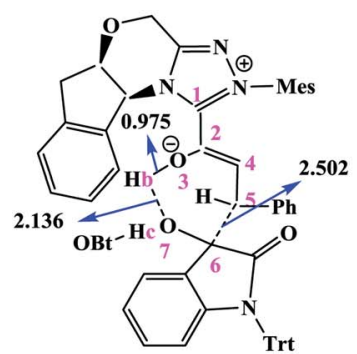

TS4(SR)

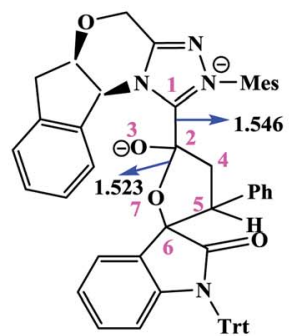

IM6(SR)

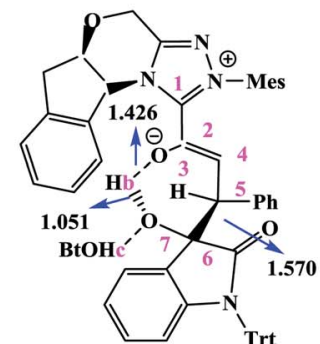

IM4(SR)

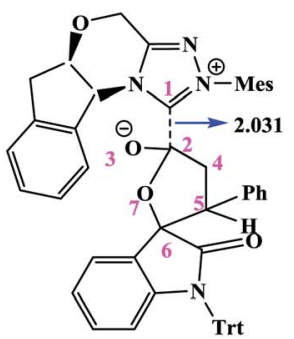

TS6(SR)

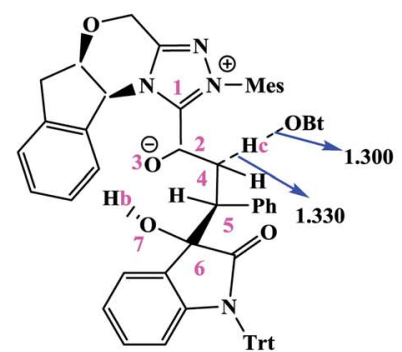

TS5(SR)

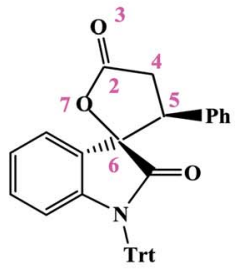

P(SR)

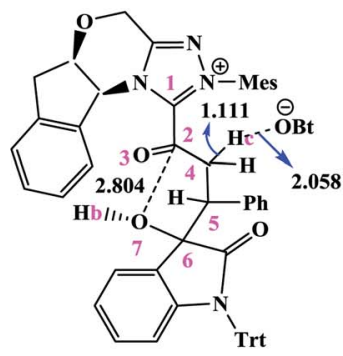

IM5(SR)

Fig. 2 Free energy profile obtained at SMD(THF)/M06-2X/6-311++G(d,p) level $\left(\mathrm{kcal} \mathrm{mol}^{-1}\right)$ and optimized structures for steps IV-VI. Bbond lengths are given in $\AA$.

TS4(SR) and TS4(RS), which responsible for enantioselectivity, is $2.3 \mathrm{kcal} \mathrm{mol}^{-1}$ corresponding to an enantiomeric excess of 96\%. The computed enantioselectivity is in good agreement with the experimental reported value (93\%). Similarly, the energy difference between TS4(SR) and TS4(RR), which is related to diastereoselectivity, is $1.9 \mathrm{kcal} \mathrm{mol}^{-1}$. This energy difference corresponds to a diastereomeric ratio of $92 \%$, which is in good agreement with the experimentally observed de of $91 \%$ (diastereomeric ratio $>20: 1$ ).

Furthermore, in order to better understand the origin of stereoselectivity of the NHC-catalyzed $[3+2]$ annulation reaction, we performed the noncovalent interaction (NCI) analysis ${ }^{21}$ which is demonstrated to be able to distinguish the strong interactions as well as the repulsion interactions. NCI analysis results for the stereoselectivity-determining transition states TS3(RR), TS3(RS), TS3(SR) and TS3(SS) are presented in Fig. 3. As depicted in Fig. 3, it is clear that a large green cloud between the $\pi$-systems of the NHC-bounded homoenolate (IM3-part) and HOBt is observed in TS3(SR), but absent in the other transition states. In addition, the repulsion interactions exist in TS3(RR), TS3(RS) and TS3(SS). Moreover, a number of noncovalent interactions including $\pi \cdots \pi$ interactions, lone pair (LP) $\cdots \pi$ interactions and $\mathrm{C}-\mathrm{H} \cdots \pi$ interactions are identified in TS3(SR). Therefore, TS3(SR) is more stable than the other transition states (TS3(RR), TS3(RS) and TS3(SS)), which is in good agreement with the experimentally observed enantioselectivity. 


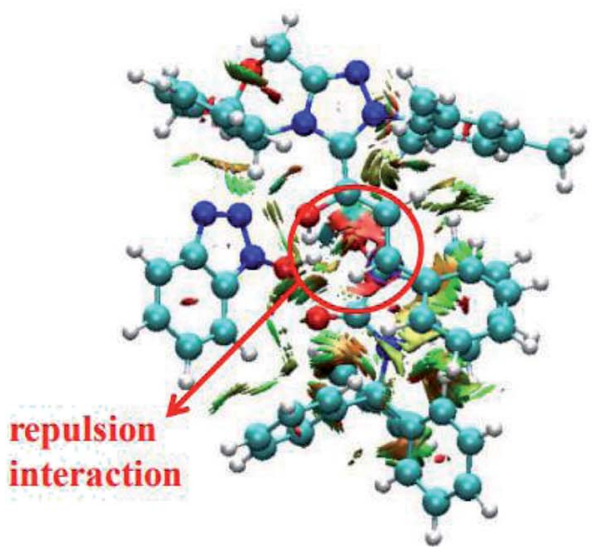

TS3(RR)

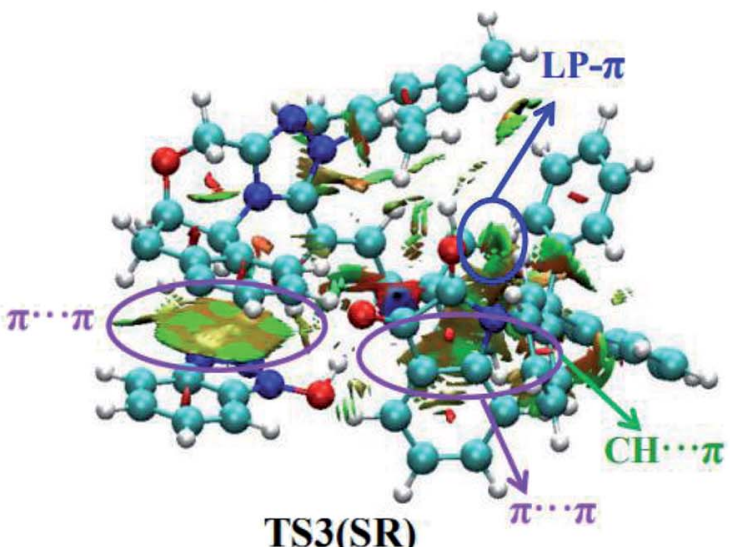

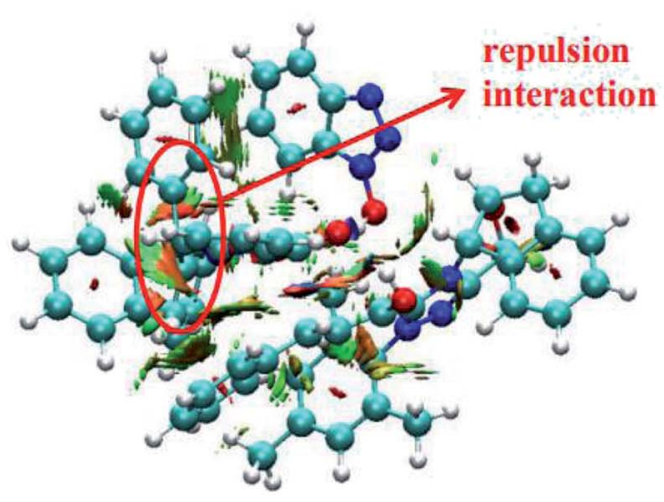

TS3(RS)

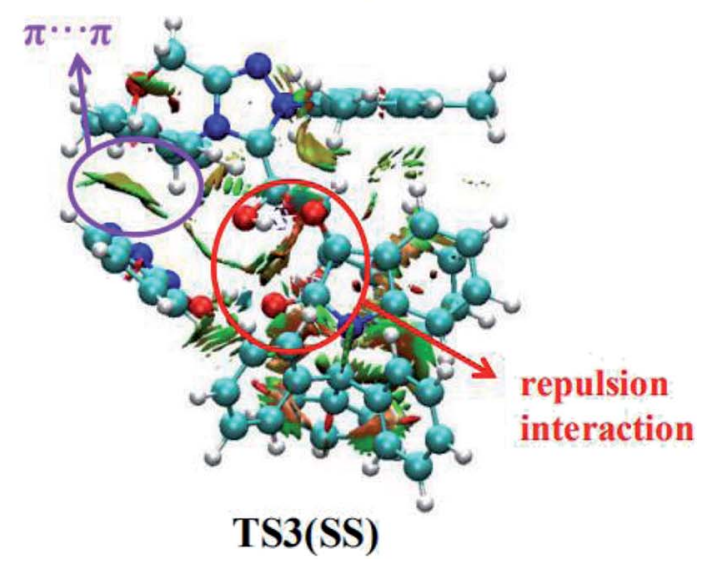

Fig. 3 Noncovalent interactions analysis (blue, strong interaction; green, weak interaction; and red, strong repulsion) for stereoselective transition states TS3(RR), TS3(RS), TS3(SR) and TS3(SS).

\subsection{The nature of catalyst}

In this section, global reactivity indexes (GRIs) analysis was carried out in order to understand the role of the NHC catalyst. The results are presented in Table 1 . In GRI analysis, the molecular global electrophilicity character represented by the electrophilicity index $\omega$, can be derived from the following expression, $\omega=\left(\mu^{2} / 2 \eta\right)(\mathrm{eV}){ }^{22}$ where $\mu$ and $\eta$ are chemical potential and chemical hardness, respectively. $\mu$ and $\eta$ can be calculated from the one-electron energies of the highest occupied molecular orbital (HOMO) and the lower unoccupied molecular orbital (LUMO), $\varepsilon_{\mathrm{H}}$ and $\varepsilon_{\mathrm{L}}$ with the expressions $\mu \approx$ $\left(\varepsilon_{\mathrm{H}}-\varepsilon_{\mathrm{L}}\right) / 2$ and $\eta \approx\left(\varepsilon_{\mathrm{L}}-\varepsilon_{\mathrm{H}}\right)$, respectively. ${ }^{23}$ Within the KohnSham scheme, ${ }^{24}$ the empirical (relative) nucleophilicity index $N^{25}$ introduced by Domingo et al. was written as $N=\varepsilon_{\mathrm{H}(\mathrm{Nu})}-$ $\varepsilon_{\mathrm{H}(\mathrm{TCE})}$. The nucleophilicity scale was referenced to tetracyanoethylene (TCE). Table 1 shows that from R1 to IM01, the electronic chemical potential increases $(-4.10 \mathrm{eV} v s .-3.46 \mathrm{eV})$, which is consistent with what we found in NBO charge analysis, i.e., the charge goes from NHC to R1. Table 1 also shows that the coupling of NHC catalyst with carboxylic esters R1 strengthens its nucleophilicity (the nucleophilicities of IM2 $(4.96 \mathrm{eV})$ and IM3 $(5.40 \mathrm{eV})$ are larger than that of $\mathbf{R 1}, N=2.67 \mathrm{eV})$, but weakens its electrophilicity (the electrophilicity of IM2 (IM3) is
Table 1 Chemical hardness ( $\eta$, in eV), electronic chemical potential, ( $\mu$, in $\mathrm{eV})$, global electrophilicity, $(\omega$, in eV), and global nucleophilicity $(N$, in eV) of selected structures involved in the NHC-catalyzed cycloaddition reaction

\begin{tabular}{lllll}
\hline Species & $\eta$ & $\mu$ & $\omega$ & $N$ \\
\hline R1 & 7.66 & -4.10 & 1.10 & 2.67 \\
IM01 & 7.05 & -3.46 & 0.85 & 3.61 \\
IM2 & 5.71 & -2.77 & 0.67 & 4.96 \\
IM3 & 4.85 & -2.77 & 0.79 & 5.40 \\
\hline
\end{tabular}

smaller than that of R1, $0.67(0.79) \mathrm{eV} v s .1 .10 \mathrm{eV})$. The GRI results suggest that the coordination of NHC to R1 makes the nucleophilic addition to $\mathbf{R} 2$ easier.

\section{Conclusion}

The reaction mechanism of the NHC-catalyzed cycloaddition reaction between carboxylic esters and isatins generating spirooxindole lactones with high enantio- and diastereoselectivities has been investigated by using density functional theory (DFT) calculations at SMD(THF)/M06-2X/6-311++G(d,p) level. The role of the additive HOBt is also examined in detail. 
The current computations reveal that the catalytic cycle comprises six steps: the NHC catalyst first attacks carboxylic ester, followed by $\alpha-\mathrm{C}-\mathrm{H}$ deprotonation gives the enolate intermediate. Subsequently, proton transfer occurs leading to the homoenolate intermediate and the next step is the stereoselective $\mathrm{C}-\mathrm{C}$ bond formation. The fifth step is the generation of lactone intermediate and finally liberation of catalyst gives the cycloaddition product. DFT results reveal that the additive HOBt plays a critical role both in the proton transfer and in the stereoselective $\mathrm{C}-\mathrm{C}$ formation. The activation barriers both for the proton transfer and for the stereoselective $\mathrm{C}-\mathrm{C}$ bond formation are much lower in the presence of HOBt. The computed stereoselectivity in the presence of HOBt agrees very good with the experimentally reported enantioselectivity (computed 96\%, experimental 93\%) as well as diastereoselectivity (computed 92\%, experimental 91\%). The origin of stereoselectivity is traced to differential $\pi \cdots \pi$ stacking, C-H $\cdots$ $\pi$, lone pair (LP) $\cdots \pi$ and repulsion interactions that exist in the stereoselective-determining $\mathrm{C}-\mathrm{C}$ bond formation transition state. These results should provide helpful insights for understanding the detailed reaction mechanism and the significant role of the HOBt additive.

\section{Conflicts of interest}

There are no conflicts of interest to declare.

\section{Acknowledgements}

This work is supported by the National Natural Science Foundation of China (No. 21403024), and National Supercomputing Center in Shenzhen.

\section{References}

1 (a) L. Wang, J. Xiao and T. P. Loh, ChemCatChem, 2014, 6, 1183-1185; (b) K. J. R. Murauski, A. A. Jaworskia and K. A. Scheidt, Chem. Soc. Rev., 2018, 47, 1773-1782; (c) D. F. Chen, T. C. K. Chu and T. Rovis, J. Am. Chem. Soc., 2017, 139, 14897-14900.

2 (a) Z. G. Hajos and D. R. Parrish, J. Org. Chem., 1974, 39, 1615-1621; (b) B. List, R. A. Lerner and C. F. III Barbas, J. Am. Chem. Soc., 2000, 122, 2395-2396; (c) W. Notz, F. Tanaka and C. F. III Barbas, Acc. Chem. Res., 2004, 37, 580-591; (d) S. Mukherjee, J. W. Yang, S. Hoffmann and B. List, Chem. Rev., 2007, 107, 5471-5569; (e) A. J. B. Watson, D. W. C. Macmillan, Y. Wang, L. Deng, S. Shirakawa and K. Maruoka, in Catalytic Asymmetric Synthesis, ed. I. Ojima, John Wiley \& Sons, Hoboken, NJ, 3rd edn, 2010, ch. 2, pp. 37-117.

3 (a) G. Yan and A. J. Borah, Org. Chem. Front., 2014, 1, 838842; (b) Z. Huang and G. Dong, Tetrahedron Lett., 2014, 55, 5869-5889.

4 (a) F. Glorius, N-heterocyclic carbene in catalysis - an introduction, Springer-Verlag, Berlin, Heidelberg, 2006, vol. 21, p. 1; (b) S. P. Nolan, Acc. Chem. Res., 2010, 44, 91-100; (c) D. Zhang and G. F. Zi, Chem. Soc. Rev., 2015, 44, 1898-
1921; (d) C. Chen, M. H. Kim and S. H. Hong, Org. Chem. Front., 2015, 2, 241-247.

5 (a) D. Enders, O. Niemeier and A. Henseler, Chem. Rev., 2007, 107, 5606-5655; (b) F. Glorius and K. Hirano, Nucleophilic carbenes as organocatalysts, Springer-Verlag, Berlin, Heidelberg, 2008, vol. 2, p. 159; (c) J. L. Moore and T. Rovis, Top. Curr. Chem., 2010, 291, 77-144; (d) D. Enders and T. Balensiefer, Acc. Chem. Res., 2004, 37, 534-541; (e) V. Nair, S. Vellalath and B. P. Babu, Chem. Soc. Rev., 2008, 37, 269126981; $(f)$ M. Fèvre, J. Pinaud, Y. Gnanou, J. Vignolle and D. Taton, Chem. Soc. Rev., 2013, 42, 2142-2172.

6 (a) M. He, J. R. Struble and J. W. Bode, J. Am. Chem. Soc., 2006, 128, 8418-8420; (b) J. J. Song, Z. Tan, J. T. Reeves, N. K. Yee and C. H. Senanayake, Org. Lett., 2007, 9, 10131016; (c) D. A. DiRocco, K. M. Oberg, D. M. Dalton and T. Rovis, J. Am. Chem. Soc., 2009, 131, 10872-10874; (d) Y. Kayaki, M. Yamamoto and T. Ikariya, Angew. Chem., Int. Ed., 2009, 48, 4194-4197; (e) D. Enders, A. Grossmann, J. Fronert and G. Raabe, Chem. Commun., 2010, 46, 62826284; (f) J. Kaeobamrung, M. C. Kozlowski and J. W. Bode, Proc. Natl. Acad. Sci. U. S. A., 2010, 107, 20661-20665; (g) D. E. A. Raup, B. Cardinal-David, D. Holte and K. A. Scheidt, Nat. Chem., 2010, 2, 766-771; (h) Q. Kang and Y. Zhang, Org. Biomol. Chem., 2011, 9, 6715-6719; $(i)$ S. J. Ryan, L. Candish and D. W. Lupton, J. Am. Chem. Soc., 2011, 133, 4694-4697; (j) T. Jousseaume, N. E. Wurz and F. Glorius, Angew. Chem., Int. Ed., 2011, 50, 1410-1414; (k) D. A. DiRocco and T. Rovis, J. Am. Chem. Soc., 2011, 133, 10402-10405; (l) Z. Fu, J. Xu, T. Zhu, W. W. Y. Leong and Y. R. Chi, Nat. Chem., 2013, 5, 835-839; $(\mathrm{m}) \mathrm{J}$. Chen and Y. Huang, Nat. Commun., 2014, 5(1-8), 3437; (n) Z. Jin, S. Chen, Y. Wang, P. Zheng, S. Yang and Y. R. Chi, Angew. Chem., Int. Ed., 2014, 53, 13506-13509; (o) V. Yatham, J. M. Neudörfl, N. E. Schlörer and A. Berkessel, Chem. Sci., 2015, 6, 3706-3710; (p) B. S. Li, Y. Wang, Z. Jin, P. Zheng, R. Ganguly and Y. R. Chi, Nat. Commun., 2015, 6, 62076211; (q) C. Guo, M. Fleige, D. Janssen-Müller, C. G. Daniliuc and F. Glorius, Nat. Chem., 2015, 7, 842-848; (r) K. Yamashita, S. Hase, Y. Kayaki and T. Ikariya, Org. Lett., 2015, 17, 2334-2337; (s) Y. Nakano and D. W. Lupton, Angew. Chem., Int. Ed., 2016, 55, 3135-3139; (t) C. Zhao, F. Li and J. Wang, Angew. Chem., Int. Ed., 2016, 55, 18201824; $(u)$ S. R. Yetra, S. Mondal, S. Mukherjee, R. G. Gonnade and A. T. Biju, Angew. Chem., Int. Ed., 2016, 55, 268-272.

7 (a) X. N. Wang, P. L. Shao, H. Lv and S. Ye, Org. Lett., 2009, 11, 4029-4032; (b) X. L. Huang, X. Y. Chen and S. Ye, J. Org. Chem., 2009, 74, 7585-7587; (c) J. Douglas, J. E. Taylor, G. Churchill, A. M. X. Slawin and A. D. Smith, J. Org. Chem., 2013, 78, 3925-3938; (d) X. N. Wang, L. T. Shen and S. Ye, Org. Lett., 2011, 13, 6382-6385; (e) T. Wang, X. L. Huang and S. Ye, Org. Biomol. Chem., 2010, 8, 50075010; (f) H. M. Zhang, Z. H. Gao and S. Ye, Org. Lett., 2014, 16, 3079-3081.

8 (a) X. Q. Fang, X. K. Chen and Y. R. Chi, Org. Lett., 2011, 13, 4708-4711; (b) L. M. Fang, F. Wang, P. J. Chua, Y. B. Lv, L. J. Zhong and G. F. Zhong, Org. Lett., 2012, 14, 2894-2897. 
9 (a) H. Lu, J. Y. Liu, C. G. Li, J. B. Lin, Y. M. Liang and P. F. Xu, Chem. Commun., 2015, 51, 4473-4476; (b) S. H. Hu, B. Y. Wang, Y. Zhang, W. F. Tang, M. Y. Fang, T. Lu and D. Du, Org. Biomol. Chem., 2015, 13, 4661-4667; (c) S. R. Yetra, S. Mondal, E. Suresh and A. T. Biju, Org. Lett., 2015, 17, 1417-1420; (d) J. D. Tessier, E. A. O'Bryan, T. B. H. Schroeder, D. T. Cohen and K. A. Scheidt, Angew. Chem., Int. Ed., 2012, 124, 5047-5051; (e) Z. Q. Liang, Z. H. Guo, W. Q. Jia and S. Ye, Chem.-Eur. J., 2015, 21, 1868-1872; (f) C. Guo, M. Schedler, C. G. Daniliuc and F. Glorius, Angew. Chem., Int. Ed., 2014, 53, 10232-10236; (g) A. G. Kravina, J. Mahatthananchai and J. W. Bode, Angew. Chem., Int. Ed., 2012, 51, 9433-9436; (h) Y. Zhang, Y. Y. Lu, W. F. Tang, T. Lu and D. Du, Org. Biomol. Chem., 2014, 12, 3009-3015.

10 (a) J. Izquierdo, A. Orue and K. A. Scheidt, J. Am. Chem. Soc., 2013, 135, 10634-10637; (b) Y. W. Xie, Y. L. Que, T. J. Li, L. Zhu, C. X. Yu and C. S. Yao, Org. Biomol. Chem., 2015, 13, 1829-1835; (c) H. Lv, W. Q. Jia, L. H. Sun and S. Ye, Angew. Chem., Int. Ed., 2013, 125, 8769-8772.

11 F. Xu, S. R. Yuan, M. Z. Miao and Z. K. Chen, J. Org. Chem., 2016, 81, 11454-11460.

12 Y. Zhao and D. G. Truhlar, Theor. Chem. Acc., 2007, 120, 215241.

13 (a) H. Xue, D. Jiang, H. Jiang, C. W. Kee, H. Hirao, T. Nishimura, M. W. Wong and C. H. Tan, J. Org. Chem., 2015, 80, 5745-5752; (b) M. W. Wong and A. M. E. Ng, Aust. J. Chem., 2014, 67, 1100-1109; (c) H. Yang and M. W. Wong, J. Am. Chem. Soc., 2013, 135, 5808-5818; (d) E. H. Krenske, E. C. Davison, I. T. Forbes, J. A. Warner, A. L. Smith, A. B. Holmes and K. N. Houk, J. Am. Chem. Soc., 2012, 134, 2434-2441; (e) H. Yang and M. W. Wong, J. Org. Chem., 2011, 76, 7399-7405; (f) Y. Zhao and D. G. Truhlar, Acc. Chem. Res., 2008, 41, 157-167.

14 C. Gonzalez and H. B. Gonzalez, J. Phys. Chem., 1990, 94, 5523-5527.

15 A. V. Marenich, C. J. Cramer and D. G. Truhlar, J. Phys. Chem. $B, 2009,113,6378-6396$.

16 (a) E. D. Glendening, A. E. Reed, J. E. Carpenter and F. Weinhold, NBO Version 3.1, Theoretical Chemistry Institute, University of Wisconsin, Madison, WI, 1996; (b) A. E. Reed, L. A. Curtiss and F. Weinhold, Chem. Rev.,
1988, 88, 899-926; (c) J. P. Foster and F. Weinhold, J. Am. Chem. Soc., 1980, 102, 7211-7218.

17 M. J. Frisch, G. W. Trucks, H. B. Schlegel, G. E. Scuseria, M. A. Robb, J. R. Cheeseman, G. Scalmani, V. Barone, B. Mennucci, G. A. Petersson, H. Nakatsuji, M. Caricato, X. Li, H. P. Hratchian, A. F. Izmaylov, J. Bloino, G. Zheng, J. L. Sonnenberg, M. Hada, M. Ehara, K. Toyota, R. Fukuda, J. Hasegawa, M. Ishida, T. Nakajima, Y. Honda, O. Kitao, H. Nakai, T. Vreven, J. A. Montgomery, Jr., J. E. Peralta, F. Ogliaro, M. Bearpark, J. J. Heyd, E. Brothers, K. N. Kudin, V. N. Staroverov, T. Keith, R. Kobayashi, J. Normand, K. Raghavachari, A. Rendell, J. C. Burant, S. S. Iyengar, J. Tomasi, M. Cossi, N. Rega, J. M. Millam, M. Klene, J. E. Knox, J. B. Cross, V. Bakken, C. Adamo, J. Jaramillo, R. Gomperts, R. E. Stratmann, O. Yazyev, A. J. Austin, R. Cammi, C. Pomelli, J. W. Ochterski, R. L. Martin, K. Morokuma, V. G. Zakrzewski, G. A. Voth, P. Salvador, J. J. Dannenberg, S. Dapprich, A. D. Daniels, O. Farkas, J. B. Foresman, J. V. Ortiz, J. Cioslowski and D. J. Fox, Gaussian 09 (Revision D.01), Gaussian, Inc., Wallingford CT, 2013.

18 (a) Q. Zhang, H. Z. Yu and Y. Fu, Org. Chem. Front., 2014, 1, 614-624; (b) J. Mahatthananchai and J. W. Bode, Acc. Chem. Res., 2013, 47, 696-707.

19 (a) Y. Wang, D. Wei, Y. Wang, W. Zhang and M. Tang, ACS Catal., 2016, 6, 279-289; (b) Y. Wang, D. Wei and M. Tang, J. Org. Chem., 2017, 82, 13043-13050; (c) Y. Wang, Y. Qiao, D. Wei and M. Tang, Org. Chem. Front., 2017, 4, 1987-1998; (d) Y. Wang, D. Wei and W. Zhang, ChemCatChem, 2018, 10, 338-360.

20 D. Y. Curtin, Rec. Chem. Prog., 1954, 15, 111-128.

21 T. Lu and F. W. Chen, J. Comput. Chem., 2012, 33, 580-592.

22 R. G. Parr, L. V. Szentpály and S. Liu, J. Am. Chem. Soc., 1999, 121, 1922-1924.

23 (a) R. G. Parr and W. Yang, Density Functional Theory of Atoms and Molecules, Oxford University Press, New York, 1989; (b) R. G. Parr and R. G. Pearson, J. Am. Chem. Soc., 1983, 105, 7512-7516.

24 W. S. Kohn and L. J. Sham, Phys Rev., 1965, 140, 1133-1138. 25 L. R. Domingo, E. Chamorro and P. Pérez, J. Org. Chem., 2008, 73, 4615-4624. 